\title{
"I was scared about just the whole thing... it made me feel better." The effect of unit tours on pediatric patients in the perioperative setting
}

\author{
Lynda J. Dimitroff ${ }^{* 1}$, Lynn W. Nichols ${ }^{2}$ \\ ${ }^{1}$ Education and Research Consultant, Rochester, NY, United States \\ ${ }^{2}$ Department of Nursing Research \& Evidence-Based Practice, Rochester General Hospital, Rochester, NY, United States
}

Received: February 13, 2017

DOI: $10.5430 /$ jnep.v7n10p129

\author{
Accepted: April 23, 2017 \\ Online Published: May 30, 2017
}

URL: https://doi.org/10.5430/jnep.v7n10p129

\begin{abstract}
Objective: Anxiety is a major issue for surgical patients during the perianesthesia period, especially pediatric patients and their families. The surgical experience can be extremely stressful to children and their caregivers. Offering preoperative tours to children and their families may increase their sense of control and positively affect their overall perioperative experience. The purpose of the research was to explore the effect of unit tours on pediatric patients in the perioperative setting. The research question for this study was: What is the effect of unit tours on pediatric patients in the perioperative setting? The tours implemented during the study were designed and conducted specifically for this study.

Methods: Naturalistic inquiry and descriptive qualitative were used in this study. The sample included 33 children, 7-11 years old (y.o.) who were scheduled for otolaryngological and urological surgeries (minor procedures) through the Ambulatory Surgery Center at a 528-bed acute-care facility in western New York, and their parents. The sample size of 33 children was appropriate for this qualitative study. Children excluded from the study were those: who had not participated in a tour prior to surgery; whose surgery was canceled on DOS; who were medicated prior to the interview; who had an unplanned hospital admission; and children with a medical history that would impact normal developmental stages. The primary investigator collected all of the data and was mentored through the process in a nursing research fellowship program by the director of the Department of Nursing Research. Data were collected through interviews with children, open-ended questionnaires with parents, participant observation, and record review of patient clinical data. Data from interviews and questionnaires were analyzed using constant-comparative analysis to identify emergent themes. Participant observations and clinical data were utilized in the overall analysis.

Results: Four themes were identified - two from the children's interviews and two from the parents' interviews including: Child Theme I - The children thought that the tours were very beneficial; Child Theme II - The tours provided the children with feelings of control during a stressful event; Parent Theme III - Parents believed the tours were an informative experience; and, Parent Theme IV - Parents appreciated having their questions and concerns addressed prior to surgery as well as having the opportunity to become familiar with the environment prior to their child's surgery.

Conclusions: The perioperative tours had a positive impact on anxiety and provided an understanding of the upcoming surgical experience for both the children and their parents. The tours allayed fears about the surgery, made the children feel more comfortable about the impending surgery, provided an opportunity to ask questions, and, familiarized families with the operative surgical environment. The results of this study suggest the importance of unit tours for pediatric patients and their parents. The results contribute to the limited research in the current professional literature.
\end{abstract}

Key Words: Pediatric tours, Preoperative tours, Pediatric surgery, Pediatric research, Surgical center tours, Pediatric anxiety, Pediatric preoperative education, Preoperative preparation programs

*Correspondence: Lynda J. Dimitroff; Email: lynda.dimitroff@gmail.com; Address: Education and Research Consultant, Hinsdale Street, Rochester, NY, United States. 


\section{INTRODUCTION}

“... I didn't know where I was going. I didn't know what anything looked like. I was very scared about just the whole thing..." (Boy, 9 y.o.). The experience of surgery, with its unfamiliar routines, clothing, equipment, sights, sounds, and smells, can be extremely stressful to children and their caregivers. ${ }^{[1]}$ Pediatric surgical patients are surrounded by potentially stressful events: separation from family, fear of the unknown, loss of control, unfamiliar faces, and fear of pain. ${ }^{[2]}$

“Children's health care experiences, although physically similar to those of adults, are significantly different when viewed from a child's perspective. Unfamiliar people, places, and rituals undermine the coping strategies of children". [3] Anxiety and fear in the preoperative area on the day of surgery (DOS) is commonly observed in childre ${ }^{[1,4-6]}$ and their family members. ${ }^{[7-9]}$ It is important to note that other studies have found that parent anxiety increases the child's anxiety. ${ }^{[5,10]}$ Anxiety affects certain coping mechanisms. Coping behaviors affect cooperation and, emotional and physical responses in pediatric patients (PP). Life experiences can have a positive or negative impact on a child's development. Offering preoperative tours to children and their families may increase their sense of control and positively affect their overall perioperative experience. Preoperative tours may help familiarize the child with the surgical environment and reduce anxiety about ${ }^{[11]}$ the "venture into the unknown of the hospital". ${ }^{[12]}$

\subsection{Purpose}

The purpose of this study was to explore the effect of unit tours on PP in the perioperative setting. There were two aims of this study including to: 1) determine if unit tours in the perioperative setting prior to children's surgery assisted children 7-11 y.o. in understanding what would occur during their admission and reduce their anxiety; and, 2) help the nursing profession understand the effects of pediatric unit tours in the perioperative setting on children and parents and, to add evidence to the professional literature on how best to treat children and parents scheduled for surgery. The main research question for this study was: What was the effect of unit tours of the perioperative setting on PP and their parents?

\subsection{Significance to nursing}

Positive perianesthesia outcomes for PP and their families are linked closely with successful preoperative education. Murphy-Taylor ${ }^{[13]}$ supported the need for education for both parents and children and described benefits of role-playing with children. She stated that the opportunity for both children and parents to visit surgical centers has presented im- mense opportunities for combating anxiety. Increased anxiety before surgery in children is associated with increased postoperative pain, analgesic consumption, general anxiety, sleeping problems, and decreased postoperative eating improvement. ${ }^{[5]}$ The stress a child suffers preoperatively negatively impacts the child's surgical and recovery time, and ultimately, the length of hospital stay. ${ }^{[14]}$

Welcoming children and their parents to visit the surgical center prior to the child's DOS, and providing education in a relaxed and child-oriented manner, may decrease anxiety in both children and their parents. The health care market has become competitive and consumers are aware of their choices for surgical care. Parents want to feel confident their child is safe and receiving the best care available, and, hospitals are invested in patient satisfaction as well. "Preparation programs foster increases in child and parent trust in the health care setting. Parental perceptions of professional competence and quality of care also are enhanced. These factors are important in today's market-driven health care environment". [3]

This study supports the American Society of PeriAnesthesia Nurses (ASPAN) core values of patient focus, perianesthesia nurse support, learning and growth, and integrity. Surgical PP are surrounded by stressful events and the aim of this project was to implement an intervention to decrease that stress. The atmosphere in the preoperative area in ambulatory surgical center (ASC) can often be described as bustling. Operating room (OR) start time, surgeon and anesthesiologist availability, patient arrival time, preoperative assessments, medications, and education are among many factors that dictate the limited amount of time nurses have to prepare their patients immediately prior to surgery. The purpose of this study was to explore the effect of unit tours on PP in the perioperative setting.

\subsection{Literature review}

The literature included thirty articles from health care journals between 1972 and 2016. Sixteen of the reviewed articles mentioned hospital tours as part of a preadmission program. Five articles investigated preoperative coping behaviors and other preparations specific to children without mentioning tour programs. Six of the articles reviewed were specific to preoperative tours alone. Of these six articles, two were research studies. In their discussion of unit tours, Bates and Broome ${ }^{[15]}$ noted that despite the popularity of hospital tours, "very little, if any, empirical information exists to validate" ${ }^{[15]}$ their effectiveness. No current research identified the effect of pediatric unit tours where child feedback was utilized and documented along with parent/caregiver responses. 
Anxiety and postoperative pain are significant issues for PPs. In a study to investigate the relationship between preoperative anxiety and postoperative pain and behavioral recovery, Kain $^{[5]}$ recruited 241 children 5-12 y.o. who were scheduled for elective outpatient surgery. The primary end point of this study was the child's postoperative pain as assessed by pain assessment instruments and analgesic administration. The secondary end point included the child's postoperative behavioral recovery as assessed by nurses and parents. Children and their parents were followed five days before surgery and fourteen days after surgery. The investigators found that increased child anxiety before surgery was associated with increased postoperative pain, analgesic administration, general anxiety, sleeping problems, and decreased postoperative eating improvement. ${ }^{[5]}$

Tours of the perioperative area prior to surgery had benefits to PPs. Marriner ${ }^{[16]}$ studied eight children - four in a control group and four in an intervention. The control group of children was admitted and went through the "normal ward routine, ... the DOS". ${ }^{[16]}$ The children in the research group were invited to visit the hospital three days before their scheduled admission date, given coloring books "introducing relevant visual aids", ${ }^{[16]}$ of hospital related equipment including oxygen masks, hospital gowns, surgical caps, and stretchers. Preoperative and postoperative reactions from both groups were compared using a numeric scale. Marriner ${ }^{[16]}$ observed that the behaviors of the research group demonstrated less anxiety and a smoother return to normal activities postoperatively.

Thompson ${ }^{[17]}$ studied 20 patients, 6-10 y.o. to determine if preoperative hospital visits produce or reduce anxiety in PP. Physical and emotional status were recorded prior to surgery and afterwards, a questionnaire given to the parent was used to determine the child's adjustment to the hospital setting, and the child's anxiety was evaluated in five areas both before and after surgery. The children in this study were premedicated prior to surgery and the type of pre-medication the children received was not specified. Data analysis showed significantly lower anxiety in the experimental group following surgery. Limitations of these studies included small sample sizes, ${ }^{[16]}$ Thompson, ${ }^{[17]}$ inexperienced researchers, ${ }^{[16]}$ and the child being pre-medicated before surgery which may have influenced the anxiety prior to surgery and the postoperative anxiety readings. ${ }^{[17]}$

In a study conducted by Brewer et al. ${ }^{[18]}$ child life specialists utilized preoperative tours surgical suite and education to determine if children, 5-11 y.o., prepared for elective otolaryngology surgery exhibited less anxiety postoperatively than those who received routine standard of care. The intervention

Published by Sciedu Press group of 80 children and their families took a 20-minute tour of the surgical center and were provided developmentally appropriate explanations of the surgical process. ${ }^{[18]}$ The control group $(n=62)$ was provided with diversionary activities such as children's movies, and, arts and crafts. Children's anxiety was assessed by the Child Drawing: Hospital (CD:H) instrument. Findings showed that children in the control group had a statistically significant increase in their anxiety levels from the preoperative to postoperative drawings when compared to the anxiety scores of the children in the intervention group. The intervention group had a non-significant decrease in anxiety from the preoperative anxiety scores to their postoperative anxiety scores. These results support previous research that tours and relevant educational preparation for procedures reduced anxiety in those prepared for the setting and procedure compared to those who did not have a similar preparation. ${ }^{[18]}$ Though there was a positive need for preoperative preparation, this research focused primarily on the role of a child life specialist in the preparation of children and parents for surgery. Also, the children's anxiety level and response to the program was determined by the use of drawings and not self-report.

There is minimal evidence in the literature on the benefits of surgical preparation of children and the outcomes of that preparation with most being non-empirical and anecdotal. Unit tours have been described as being one modality to prepare and educate children and their parents for a hospital admission. No current research was identified that specifically studied the effect of unit tours on PP and their families where child feedback was documented and analyzed with parent/caregiver responses.

\subsection{Theoretical framework}

The theoretical models utilized for this study were the Lazarus Theory of Stress and Coping, ${ }^{[2]}$ and Jean Piaget's Theory of Child Development. ${ }^{[19]}$ Piaget's theory includes the belief that children adapt their thinking to include new ideas because additional information furthers understanding. ${ }^{[20]}$ Santrock ${ }^{[20]}$ explained that according to Piaget's view, two processes underlie the individual's understanding of the world - organization, and adaptation. To make sense of our world, we organize our experiences by connecting one idea to another. In Piaget's theory, children adapt their thinking to include new ideas. Adaptation occurs in two ways - assimilation and accommodation.

"Assimilation occurs when individuals incorporate new information into their existing knowledge. Accommodation occurs when individuals adjust to new information". ${ }^{[20]}$ Giving children an opportunity to visit the ASC prior to their surgery date may allow them to assimilate new information 
and in turn accommodate this information to help them more easily adjust to the surgical environment, the idea of having a surgical procedure, and separation from their caregivers.

The concrete-operational stage of Piaget's Theory, occurs between 7-11 y.o. In this third stage, children can perform operations and illustrate logical thought processes. ${ }^{[20]}$ Operations are defined as "internalized sets of actions that allow the child to do mentally what was done physically before"[20] and children think logically about objects and events. The children enrolled in this study ranged from 7-11 y.o. This age range was chosen due to the theoretical ability of these children to apply assimilation, accommodation, and adaptation to the information presented to them during the tour and to provide logical and thoughtful feedback during the preoperative interview.

Lazarus' Theory of Stress and Coping ${ }^{[2]}$ describes coping as the process used to alter, manage, and tolerate a disturbance in a personal or situational relationship. ${ }^{[21]}$ According to Lazarus, ${ }^{[2]}$ the child's cognitive appraisal of the event will determine the coping behaviors used. ${ }^{[18]}$ "Cognitive appraisal is Lazarus's term for children's interpretations of events in their lives as harmful, threatening, or challenging, and their determination of whether they have the resources to effectively cope with the events". [20]

The child's coping behaviors are affected by many factors such as the child's age, developmental level, prior hospitalizations, and prior encounters with the medical profession. ${ }^{[18]}$ Children who received detailed preoperative information about surgical procedures manifested more vigilant coping modes compared with children who received little or general information. ${ }^{[21]}$ Preoperative unit tours allow children and their caregivers an opportunity to ask questions and become familiar with the surgical center environment, equipment, and staff prior to the DOS.

\section{MethodS}

\subsection{Method and study tradition}

The research method used for this study was naturalistic inquiry with a qualitative descriptive tradition. Qualitative methods were chosen for two reasons. The first reason was to assist PP by understanding the effects of unit tours in the perioperative setting. "Qualitative methods are used when little is known about a phenomenon...". [22] The second reason qualitative inquiry was chosen was because of lack of information in the professional literature on the effect of unit tours on PP in the perioperative setting.

Naturalistic inquiry deals with the issue of human complexity by exploring the phenomenon directly. ${ }^{[23]}$ Naturalistic inquiry was used to explore the effects of unit tours on the participants and to give voice to their thoughts and views regarding their unit tour experience in the ASC. Qualitative descriptive framed the conversations held with the children in the preoperative interviews, and in the responses of the caregivers through the postoperative questionnaire. Clinical data were obtained through documented assessments of the child's behavior in the preoperative setting and collection of post-anesthesia information.

\subsection{Participants \& setting}

The target participants in this study were children $(n=33)$ 7-11 y.o., and their parents/caregivers who were patients of two otolaryngology or urology practices in western New York. These two practices scheduled many pediatric surgical cases in the ambulatory surgical center of the participating hospital and were currently active in preadmission education. All children in this age group who were having surgery and their families were offered the opportunity to schedule a unit tour and participate in the study. Purposeful sampling, appropriate for qualitative research was used for this study.

The logic and power of purposeful sampling lies in selecting information-rich cases for study in depth. Information-rich cases are those from which one can learn a great deal about issues of central importance to the purpose of the research, thus the term purposeful sampling. ${ }^{[24]}$

\subsection{Exclusion criteria}

The exclusion criteria (see Table 1) for this study included children: who had not participated in a tour; whose surgery was canceled on the DOS due to illness, non-compliance to NPO status, or other factors effecting patient safety perioperatively; who were medicated with a sedative prior to the preoperative interview; who were unplanned overnight hospital admissions due to surgical or anesthesia-related complications; and, any children who had a medical history that would have impacted normal developmental stages, such as autism or uncontrolled attention deficit disorder (ADD).

Table 1. Exclusion criteria

\begin{tabular}{l} 
Children excluded from the study included those: \\
- who had not participated in a tour; \\
- whose surgery was canceled due to illness; \\
- who were non-compliant with NPO status; \\
- who had factors effecting patient safety perioperatively; \\
interview; \\
- who were unplanned overnight hospital admissions due to \\
- surgical or anesthesia related complications; and, \\
developmed a medical history that would impact normal \\
\hline
\end{tabular}


The setting for this study was an ASC in an acute-care, community teaching hospital in western New York. The child's initial exposure to the ASC was the day of their tour. On the scheduled DOS, preoperative interviews with the child occurred in the preoperative holding area by the Co-PI. The postoperative questionnaires to the parents/caregivers were distributed to complete independently during the child's stay in the Phase II recovery areas. The Phase II areas included the postoperative lounge (POL) and the sub-acute (SA) area. Children were required to stay in the SA area for approximately three to four hours after having a tonsillectomy and approximately two hours after having an adenoidectomy. All other PP stayed in the POL until discharge. Children having other surgeries were required to stay a minimum of one hour after receiving anesthesia and their admission to the recovery room. Due to the administration of anesthesia and other medications, children typically slept during their stay in the POL and SA areas.

\subsection{Ethical protection of participants}

The influence and guidance of experienced mentorship, and the requirement of IRB approval, assured adherence to the standards of scientific integrity within this study. To protect the rights of human subjects, approvals were obtained from the participating institution's Nursing Research Committee (NRC) and the Institutional Review Board. Due to the involvement of children in this study, consent was obtained from a parent/caregiver and assent from the child prior to the child's participation in the study. The primary investigator (PI), nursing research mentor (NRM), and research assistants (RAs) completed the National Institute of Health Protecting Human Research Participants course as per institution policy.

\subsection{Data analysis}

All research data and materials were secured in a locked file cabinet in the PI's area and made accessible to the PI and NRM only.

\subsection{Data collection}

Data collection commenced following NRC and IRB approval. An in-service to orient three research assistants on the project regarding tour and data collection procedures preceded the start of the study.

The participant's initial notification of the study and unit tours was at the preoperative visit in their surgeon's office. The office staff providing preoperative education distributed the study and tour information flyer to the child's parents/caregivers. The informational flyer invited parents to contact the ASC for information regarding the study

Published by Sciedu Press and to schedule a tour. A RN trained to educate the parents/caregivers regarding the study and scheduling tours received and returned all phone calls.

\subsubsection{The ASC tour}

The ASC tour was scheduled within one week prior to the child's DOS. Two RNs were present during each tour. There was a maximum of ten children scheduled for any tour. The children were greeted in the admission area of the ASC and the tour began in the waiting room where all children received a "Tour Kit". The "Tour Kit" included a surgical hat, magnifying glass, surgical center coloring/activity book, passport booklet, and anesthesia mask. The tour mirrored the activities of the DOS admission procedures. The children were allowed to opt out of any activity in which they did not want to participate. The children proceeded to the preoperative holding area where they were instructed to write their name on a name band before it was placed on their wrist. They were shown the pajamas they would wear on the DOS, and had their height, weight, oxygen saturation, heart rate, and blood pressure assessed. The children were instructed to don their surgical hat before proceeding into the OR with instructions as to the need to keep everything clean. The tour proceeded to the recovery "wake up" room, and then to the Phase II areas. Their passport was stamped after visiting each area. Finally, the children were taken into the hallway, simulating their discharge from the unit. The children and parents/caregivers returned to the POL area for popsicles and to have the opportunity to ask questions. A photo was taken of each child and placed in her/his passport before leaving the ASC. The children were instructed to draw their favorite part of the tour in their passport and to bring the passport on their DOS. A replacement passport was provided if the child returned without their original passport on the DOS.

\subsubsection{Day of surgery/preoperative interview}

The child was admitted through the ASC on the DOS. Assessments, vital signs, and height \& weight were obtained per unit protocol in the same order as was shown on the tour. Prior to the preoperative interview, the child was asked to show their passport. The child was interviewed in the preoperative area utilizing open-ended questions (see Table 2) to allow the child to express thoughts and describe experiences in her/his own words. The PI completed an observation/behavior assessment checklist (see Table 3) documenting the child's interaction and cooperation with the preoperative process on the flow sheet and at the end of the preoperative interview form. 
Table 2. Child's interview questions

1. How do you feel today?
2. Tell me what you thought about the tour?
3. How did you feel before going on the tour?
4. How did you feel after the tour?
5. Do you think the tour helped?
6. What was your favorite part of the tour?
7. What would you tell other children about going on a tour
before they have surgery?
8. Do you have any questions?

Table 3. Observation/behavior assessment checklist

\begin{tabular}{|l|l|}
\hline Talking with parent/family & Quiet \\
Talking with a nurse & Crying \\
Involved with environment & Withdrawn \\
Playing & Combative \\
Asking questions & Sleeping \\
Cooperative & Uncooperative \\
\hline
\end{tabular}

\subsubsection{Day of surgery/post-operative questionnaire}

A questionnaire (see Table 4) was used postoperatively to determine the perception of the child's parents/caregivers on the effect of the preoperative tour on anxiety. Children were required to stay at least one hour after receiving general anesthesia. The questionnaire was given to parents/caregivers in the Phase II recovery area to be completed while waiting for their child to wake and be cleared for discharge from the ASC. If parents were unable to complete the questionnaire during the Phase II period due to the child's behavior or complications from surgery, they were asked to complete the questionnaire at home and return it to the ASC within one week in the stamped, self-addressed envelope that was provided.

Table 4. Parent questionnaire
1. What do you think about your child's hospital experience?
2. What do you think about your child's preoperative experience?
3. What was your overall experience in ambulatory surgery?

\subsubsection{Clinical data}

Clinical data were collected on each child. Postoperative heart rate and medications administered postoperatively, along with length of stay in recovery were obtained from the flow sheet and documented after child was discharged.

\subsection{Data analysis}

Data were analyzed using triangulation of all four sets of data including the interviews (children's interviews and parent's questionnaires), participant observations (nurse's observation of child's behavior prior to surgery), and a document (clinical flowsheet). Data analysis and interpretation is an on-going process in qualitative research and the principles include comprehending, synthesizing, theorizing, and recontextualizing. ${ }^{[22]}$ After each interview was transcribed, it was read, re-read, and read again. Once the process was completed all of the interviews were coded and compared. Constantcomparative analysis was used to examine and explore the data for themes. Themes from each interview were compared to the themes of all other interviews.

\section{RESUlts}

\subsection{Demographics}

Thirty-three children 7-11 y.o. were consented for this study. The 17 male children (52\%) and 16 female children (48\%) were ENT, orthopedic, or urology patients who were scheduled for ambulatory surgery. The mean age (SD) of the children was 8.64 (1.25). The most common surgical procedure was a tonsillectomy $(\mathrm{n}=23)$. The mean length of stay after surgery was 141.7 minutes (45.64). Ibuprofen (71\%) was the most common medication administered after surgery.

A total of 31 parent surveys were completed and returned. The mean time between tour and DOS was 3.5 days with a mode of one day. The longest time between tour and DOS was 12 days because of a winter holiday. A total of 31/33 transcripts were used for analysis. One unusable transcript included a child who did not talk during the interview and another child whose interview did not audio-record.

\subsection{Participant observation/behavioral checklist}

Ninety-seven percent (32/33) of the children talked with parents and nurses, were involved in the environment, played, asked questions, and demonstrated cooperative behaviors prior to surgery.

\subsection{Themes}

A total of four themes were identified during data analysis - two from the children's' interviews and two from the parent interviews. The themes included: Child Theme I - The children thought that the tours were very beneficial (five subthemes); Child Theme II - The tours provided the children with feelings of control during a stressful event (two subthemes); Parent Theme III - Parents believed the tours were an informative experience; and, Parent Theme IV - Parents appreciated having their questions and concerns addressed prior to surgery as well as having the opportunity to become familiar with the environment prior to their child's surgery. 
Table 5. Operative procedures

\begin{tabular}{lll}
\hline Surgical Procedure & $\mathbf{N}$ & $\mathbf{\%}$ \\
\hline Adenoidectomy & 1 & 3 \\
Hernia repair & 1 & 3 \\
Laryngoscopy & 1 & 3 \\
Myringotomy & 3 & 9 \\
Orchiopexy & 3 & 9 \\
Osteotomy & 1 & 3 \\
Tonsillectomy & 23 & 69 \\
Total & 33 & 100 \\
\hline
\end{tabular}

Table 6. Post-operative medications

\begin{tabular}{lll}
\hline Medication & $\mathbf{N}$ & $\mathbf{\%}$ \\
\hline Acetaminophen & 2 & 6 \\
Ibuprofen & 25 & 71 \\
Morphine & 1 & 3 \\
Combination & 2 & 6 \\
No medication & 1 & 3 \\
Not applicable & 4 & 11 \\
Total & 35 & 100 \\
\hline
\end{tabular}

Table 7. Clinical data

\begin{tabular}{lllll}
\hline & Mean (SD) & Median & Minimum & Maximum \\
\hline Age (years) & $8.64(1.25)$ & 8.00 & 7.00 & 11.00 \\
Heart rate & $107(17.29)$ & 109 & 71 & 150 \\
Length of Post-op Stay (minutes) & $141.7(45.64)$ & 148 & 51 & 222 \\
\hline
\end{tabular}

Child Theme I - The children thought that the tours were very beneficial (five sub-themes) and included five subthemes that were identified as overall experience, positive thoughts, the tour helped, peers to take the tour, and, passports and popsicles.

\subsubsection{Overall experience}

The children believed that the tour was fun. One young boy 10 y.o. responded, "I liked it. I thought it was helpful." (Boy, 10 y.o.)

\subsubsection{Positive thoughts}

One participant stated that she thought the tour was cool. "I think it was cool. I liked when we went into the operating room and the nurses were very, very nice. We rode wheelchairs." (Girl, 8 y.o.)

Another responded, "When I was coming here in the car today, I kind of had butterflies because I was kind of nervous. But since I saw you (RN friend from the tour) and everybody else, I'm not so nervous anymore." (Girl, 11 y.o.)

\subsubsection{The tour helped}

The young participants overwhelming agreed that the tour helped. One young boy gave a detailed description of how the tour helped him on the DOS. "Yes it did (help)... because I didn't know where I was going. I didn't know what anything looked like. I was very scared about just the whole thing and now that I've taken... a tour. . . I'm not so scared... I'm scared about getting cut open... I'm not very scared about where I am or what's going on... Well, I enjoyed the tour very much.... I'm actually happy that I took the tour... Well, now that I'm not really all freaked out about it Published by Sciedu Press because I know where I'm going... ." (Boy, 9 y.o.)

\subsubsection{Peers to take the tour}

The children thought that any of their friends who might be having surgery should take a tour. "I would tell them that it will make you very, very, comfortable and you might be a little bit scared at first, but after you meet everybody here and get to know where you're going and everything, you won't be so scared." (Girl, 11 y.o.)

\subsubsection{Passports and popsicles}

Finally, the children were very excited about receiving their passport, stamps in their passports, a surgical mask, and popsicles. One boy stated, "I got a stamp. Then I went to see the movie room. Then I ate popsicles." (Boy, 8 y.o.)

Child Theme II - The tours provided the children with feelings of control during a stressful event; and included two sub-themes: getting to know the environment, and, seeing the operating room.

The tour provided the children with a sense of familiarity during a stressful, scary time. One little boy said, "I felt like I knew the place better and I knew what they were going to do and all the places, what they looked like and the operating room [sic] and recovery room and stuff like that. It made me feel better. It didn't make me nervous." (Boy, 10 y.o.)

\subsubsection{Getting to know the environment}

The children commented on their comfort and familiarity with the surgical environment that they had visited during the tour. One little boy remarked, "I thought it was awesome. I was excited to see what I was doing and it made me feel not nervous because I knew what I was doing and where I 
was going." (Boy, 8 y.o.)

Another child made reference to her familiarity with the RNs and surgical area where her procedure would take place. She stated, "When I met you, I mean Debbie, RN and Betsy, RN. When I came in here, did my fake heart beat and looked at the closet with the toys. And. . when I got to sit on my bed.' (Girl, 8 y.o.)

\subsubsection{Seeing the operating room}

The children enjoyed visiting the operating room, checking out the equipment, and having fun with wheelchairs, and gurneys. "My favorite part of the tour was when I went into the operation room and we were riding wheelchairs. The nurses were very kind and nice" (Girl, 8 y.o.). Another participant said, "Well I like the operating room a lot. That was very fun. How I got to see... the inside... mad scientist lab. . because there... was the bed with all the guys working on me, yeah!" (Boy, 9 y.o.).

Theme III - Parents believed the tours were an informative experience The parents who participated in the study were very pleased with the overall experience. One parent said, "Great ... she [the child] was made to feel so special. She was smiling the whole time." One parent commented on her child's fear before the surgery and how the tour helped alleviate the fear, "Before the tour he was nervous and afraid. After [the tour] he was actually excited to come back the following day."

One parent stated that her child's needs were totally met, " $100 \%$ met [needs] all the way. Excellent."

Theme IV - Parents appreciated having their questions and concerns addressed prior to surgery as well as having the opportunity to become familiar with the environment prior to their child's surgery

The parents had their needs met and their fears eased during the tours. One parent stated, "I liked being able to come prior to the surgery so I could have time to ask all the questions I needed to ask without feeling rushed."

Another parent was so excited by the tours she said, "Excellent! Very comfortable... professional environment. We would highly recommend to others."

Table 8. Themes

\begin{tabular}{|c|c|c|}
\hline Theme \# & Theme & Sub-themes \\
\hline Child Theme I & The children thought that the tours were very beneficial. & $\begin{array}{l}\text { a. Overall experience } \\
\text { b. Positive thoughts } \\
\text { c. The tour helped } \\
\text { d. Peers to take the tour } \\
\text { e. Passports and enjoying popsicles }\end{array}$ \\
\hline Child Theme II & $\begin{array}{l}\text { The tours provided the children with control during a stressful event } \\
\text { included: getting to know the environment, and, seeing the operating room. }\end{array}$ & $\begin{array}{l}\text { a. Getting to know the environment } \\
\text { b. Seeing the operating room }\end{array}$ \\
\hline Parent Theme III & Parents believed the tours were an informative experience. & \\
\hline Parent Theme IV & $\begin{array}{l}\text { Parents appreciated having their questions and concerns addressed prior to } \\
\text { surgery as well as having the opportunity to become familiar with the } \\
\text { environment prior to their child's surgery. }\end{array}$ & \\
\hline
\end{tabular}

\section{Discussion}

The tours let kids act like kids by making an unfamiliar environment more familiar. The tours impacted the children's cognitive appraisal of the upcoming operative experience and lessened the degree to which it was perceived as threatening. The child's sense of control was increased as they became familiar with their RNs, staff, and the environment. Reality was revealed from the imaginary. The unfamiliar became familiar. The unknown became known.

The tours had a similar positive effect on the parents as well providing them with reassurance about their child's surgical experience. The parents' sense of control was increased as their questions and concerns were addressed prior to surgery and, as they became familiar with the environment where their child was being treated.

The results of this study advance nursing science in the area of the pediatric operative setting. The rich qualitative information collected, by giving a voice to our PP and their parents/caregivers has helped perianesthesia nurses gain insight into how our PP view their experience in ASC and to hear what they thought was important and beneficial. The feedback from the patient's parents/caregivers gave an additional dimension to the insight gained regarding what was most beneficial to our pediatric population and their parents/caregivers. The knowledge gained and the insight into understanding allows RNs to adjust practices to accommodate the evidence brought forth from this study. Most importantly, research advances nursing science. 


\section{Limitations}

There were several limitations which restricted the conclusions that may be drawn from this study. The limitations included a new researcher who was being mentored for this study, and participants who were chosen from only one hospital. In addition, this study included only 7-11 y.o. children. The effects of unit tours on other age and developmental groups may differ from this specific age group. The comparison of effects between varieties of preoperative interventions could be studied.

\section{Conclusions}

Offering preoperative tours to children and their families provided the children with a sense of control, and the children viewed their tour as a positive experience. The parents and caregivers of the children believed the tours were a helpful experience that increased their understanding of what would occur. Parents appreciated having their questions and concerns addressed as well as having the opportunity to become familiar with the environment prior to their children's surgery.

Perioperative tours provide an opportunity for health care providers and institutions to positively influence a child's perception and experience of a health care facility and an upcoming stressful event. "Clarification and familiarity are the keys to a less stressful perioperative experience. This ultimately impacts significantly on health care, productivity, and consequently, health care costs". [14] A preoperative tour program has the potential to give our youngest and most vulnerable surgical patients a head start at a successful hospital experience.

In conclusion, the effect that preoperative tours had on the children was summarized by one interaction the coinvestigator had with a child. When a sweet, quiet, 8 y.o. boy was asked by the co-investigator, "how did you feel when you left from your tour? He thought for a moment and then answered, "special" (Boy, 8 y.o.).

\section{Clinical implications and future research}

The results of this study suggest that health care institutions should consider providing unit tours to PP and their parents/caregivers in the perioperative setting. In addition, the children found it helpful to receive some type of reward (activity, popsicle, toy). Meeting the perioperative staff gave the children an opportunity to spend time with the staff they would see when they returned on their DOS. Other preoperative interventions to benefit children's coping behaviors on the DOS could also be examined. Finally, the tours provided parents/caregivers with familiarity and a time to ask questions and express concerns prior to their child's surgery.

\section{BIO STATEMENT}

Dr. Lynda J. Dimitroff is an Education and Research Consultant.

Dr. Lynn W. Nichols died in September 2013.

\section{ACKNOWLEDGEMENTS}

The authors of this article would like to thank Deb Farmer, RN, co-investigator, Nursing Research Fellow for generating the idea, working on the initial research proposal, and collecting data. We are grateful to the children and parents who participated in the study. Without the participants, we could not have given voice to this important issue. The authors would also like to thank Betsy Hernandez, RN, Darla Burke, LPN, and the Ambulatory Surgical Center registered nurses, surgeons, medical professionals, and staff for their support on this research project. Finally, we thank the American Society of PeriAnesthesia Nurses Nursing Research Grants Program and the KIDD Fund at Rochester General Hospital for financial support of this project.

\section{CONFLicts OF INTEREST Disclosure}

The authors declare that there were no conflicts of interest.

\section{REFERENCES}

[1] Justus R, Wilson J, Walther V, et al. Preparing children and families for surgery: Mount Sinai's multidisciplinary perspective. Pediatric Nursing. 2006; 32: 35-43. PMid:16572537

[2] Lazarus RS. Psychological stress and coping in adaptation and illness. International Journal of Psychiatry in Medicine. 1974; 5: 321333. PMid:4618837 https://doi .org/10.2190/T43T-84P3-Q DUR-7RTP

[3] Squires V. Child-focused perioperative education: helping children understand and cope with surgery. Seminars in Perioperative Nursing. 1995; 4: 80-87. PMid:7780422

Published by Sciedu Press
[4] Buckley A, Savage E. Preoperative information needs of children undergoing tonsillectomy. Journal of Clinical Nursing. 2010; 19: 2879-2887. PMid:20846232 https://doi.org/10.1111/j.13 65-2702.2010.03273.x

[5] Kain Z, Mayes L, Caldwell-Andrews A, et al. Preoperative pain, and behavioral recovery in young children undergoing surgery. Pediatrics. 2006; 118: 651-657. PMid:16882820 https://doi.org/10.154 2/peds. 2005-2920

[6] Li HC, Lopez V. Effectiveness and appropriateness of therapeutic play intervention in preparing children for surgery: A randomized control trial study. Journal of Specialists in Pediatric Nursing. 2008; 13: 63-73. PMid:18366374 https://doi.org/10.1111/j.1744 
$-6155.2008 .00138 . x$

[7] Franck LS, Spencer C. Informing parents about anaesthesia for children's surgery: A critical literature review. Patient Educ Couns. 2005; 59: 117-125. PMid:16257615 https://doi.org/10.1016/j.pe c. 2004.11 .002

[8] Li HC, Lopez V, Lee TL. Psychoeducational preparation of children for surgery: The importance of parental involvement. Patient Education and Counseling. 2007; 65: 34-41. PMid:16872785 https://doi.org/10.1016/j.pec.2006.04.009

[9] Scrimin S, Haynes M, Altoe G, et al. Anxiety and stress in mothers and fathers in the $24 \mathrm{~h}$ after their child's surgery. Child: Care, Health and Development. 2009; 35(2): 227-233.

[10] Fortier MA, Del Rosario AM, Martin SR, et al. Perioperative anxiety in children. Pediatric Anesthesia. 2010; 20: 318-322. PMid:20199609 https://doi.org/10.1111/j.1460-9592.2010.03263.x

[11] O'Shea M, Cummins A, Kelleher A. The perceived effectiveness of a pre-admission visit for children. Journal of Perioperative Practice. 2011; 21: 244-248

[12] Gustafson G. Surgery safari-a preoperative tour. Today's OR Nurse. 1980; 2: 16-19. PMid:6902592

[13] Murphy-Taylor C. The benefits of preparing children and parents for day surgery. British Journal of Nursing. 1999; 8: 801-804 PMid:10670297 https ://doi.org/10.12968/bjon.1999.8.1 2.6575

[14] Somerville L. Children love surprises... but, preoperative education programme for children. ACORN. 2001; Winter: 34-36.
[15] Bates A, Broome M. Preparation of children for hospitalization and surgery: a review of the literature. Journal of Pediatric Nursing. 1986; 1: 231 .

[16] Marriner J. A children's tour. Nursing Times. 1988; 8: 39-41.

[17] Thompson E. Preop visits-for the nurse-for the patient? AORN. 1972; 1: $77-80$.

[18] Brewer S, Gleditsch S, Syblik D, et al. Pediatric anxiety: Child life intervention in day surgery. Journal of Pediatric Nursing. 2006; 21: 13-22. PMid:16428010 https ://doi.org/10.1016/j.pedn .2005 .06 .004

[19] Simatwa MW. Piaget's theory of intellectual development and its implication for instructional management at pre-secondary school level. Educational Research and Reviews. 2010; 5: 366-371.

[20] Santrock J. Life-Span Development. Madison, Wisconsin: Brown and Benchmark; 1997. PMid:9169012

[21] Cohen F, Lazarus R. Coping with the stresses of illness. In G. C. Stone F. Cohen and NE Adler (Editors), Health Psychology. San Francisco: Jossey-Bass; 1992.

[22] Morse J, Field PA. Qualitative research methods for health professionals 2nd edition. Thousand Oaks, CA: Sage Publications; 1995.

[23] Polit D, Beck C. Essentials of nursing research, methods, appraisal, and utilization. Philadelphia: Lippincott, Williams \& Wilkins; 2006.

[24] Patton MQ. Qualitative evaluation and research methods 2nd edition. Thousand Oaks, CA: Sage Publications; 1990. 